\title{
Understanding sodium-ion diffusion in layered P2 and P3 oxides via experiments and first-principles calculations: a bridge between crystal structure and electrochemical performance
}

\author{
Shaohua Guo ${ }^{1,2,7}$, Yang Sun ${ }^{1,7}$, Jin $\mathrm{Yi}^{1}$, Kai Zhu${ }^{1}$, Pan $\mathrm{Liu}^{3}$, Yanbei Zhu ${ }^{4}$, Guo-zhen $\mathrm{Zhu}^{5}$, Mingwei Chen ${ }^{3}$, \\ Masayoshi Ishida ${ }^{2}$ and Haoshen Zhou ${ }^{1,2,6}$
}

Layered $\mathrm{Na}_{x} \mathrm{MeO}_{2}(\mathrm{Me}=$ transition metal) oxides, the most common electrode materials for sodium-ion batteries, fall into different phases according to their stacking sequences. Although the crystalline phase is well known to largely influence the electrochemical performance of these materials, the structure-property relationship is still not fully experimentally and theoretically understood. Herein, a couple consisting of $\mathrm{P} 2-\mathrm{Na}_{0.62} \mathrm{Ti}_{0.37} \mathrm{Cr}_{0.63} \mathrm{O}_{2}$ and $\mathrm{P} 3-\mathrm{Na}_{0.63} \mathrm{Ti}_{0.37} \mathrm{Cr}_{0.63} \mathrm{O}_{2}$ materials having nearly the same compositions is reported. The atomic crystal structures and charge compensation mechanism are confirmed by atomic-scale characterizations in the layered P2 and P3 structures, respectively, and notably, the relationship of the crystal structure-electrochemical performance is well defined in the layered P-type structures for the first time in this paper. The electrochemical results suggest that the P2 phase exhibits a better rate capability and cycling stability than the P3 phase. Density functional theory calculations combined with a galvanostatic intermittent titration technique indicates that the P2 phase shows a lower Na diffusion barrier in the presence of multi-Na vacancies, accounting for the better rate capability of the P2 phase. Our results reveal the relationship between the crystal structure and the electrochemical properties in P-type layered sodium oxides, demonstrating the potential for future electrode advancements for applications in sodium-ion batteries.

NPG Asia Materials (2016) 8, e266; doi:10.1038/am.2016.53; published online 22 April 2016

\section{INTRODUCTION}

To smoothly integrate renewable energy into a smart grid system, an inexpensive and efficient energy storage device is urgently needed for large-scale applications. ${ }^{1}$ The increasing costs and limited availability of lithium suggest that an alternative to lithium-ion batteries should be developed to meet the demands of large-scale energy storage. ${ }^{2-6}$ Rechargeable sodium-ion batteries have chemical storage mechanisms similar to their lithium-ion counterparts and are expected to be low cost and chemically sustainable as a result of an almost infinite supply of sodium. ${ }^{7-15}$ Meanwhile, the feasible replacement of $\mathrm{Cu}$ with $\mathrm{Al}$ current collectors (an alloying reaction does not occur between $\mathrm{Na}$ and $\mathrm{Al})$ will further reduce the substantial costs and weight for nextgeneration batteries.

Layered sodium oxide $\mathrm{Na}_{x} \mathrm{MeO}_{2}(\mathrm{Me}=3 \mathrm{~d}$ transition metal) materials, owing to their large specific capacity and reversible insertion/ extraction, have been studied intensely for sodium-ion battery applications for decades. Layered $\mathrm{Na}_{x} \mathrm{MeO}_{2}$ polytypes obtained through chemical solid-state synthesis mainly show two different structures: P2 and O3 (Figure 1). ${ }^{16}$ They have been extensively studied as electrode materials for rechargeable sodium-ion batteries. ${ }^{17,18}$ Owing to direct $\mathrm{Na}$-ion diffusion and a more open framework, the original structure of the $\mathrm{P} 2$ phases is more easily preserved during the sodium extraction process, ${ }^{19-22}$ although a partial P2-O2 phase transition is found in the literature. ${ }^{23,24}$ In contrast, the $\mathrm{O} 3$ phase always transforms to the $\mathrm{P} 3$ phase via gliding of the $\mathrm{MeO}_{2}$ slabs $(1 / 3$, $2 / 3,0)$ that results from the presence of intermediate tetrahedral sites between two octahedral sites (Figure 1). ${ }^{25}$ As two main electrochemical products, the $\mathrm{P} 2$ and $\mathrm{P} 3$ phases have the same sodium accommodation as prismatic sites. Thus far, the connection and distinction between the layered structures of $\mathrm{P} 2$ and $\mathrm{P} 3$ has been rarely

${ }^{1}$ Energy Technology Research Institute, National Institute of Advanced Industrial Science and Technology (AIST), Tsukuba, Japan; ${ }^{2}$ Graduate School of System and Information Engineering, University of Tsukuba, Tsukuba, Japan; ${ }^{3}$ WPI Advanced Institute for Materials Research, Tohoku University, Sendai, Japan; ${ }^{4}$ National Metrology Institute of Japan, National Institute of Advanced Industrial Science and Technology (AIST), Tsukuba, Japan; ${ }^{5}$ State Key Laboratory of Metal Matrix Composites, School of Materials Science and Engineering, Shanghai Jiao Tong University, Shanghai, People's Republic of China and ${ }^{6}$ Center of Energy Storage Materials \& Technology, College of Engineering and Applied Sciences, National Laboratory of Solid State Microstructures, Collaborative Innovation Center of Advanced Microstructures, Nanjing University, Nanjing, People's Republic of China 7These authors contributed equally to this work.

Correspondence: Dr P Liu, WPI Advanced Institute for Materials Research, Tohoku University, Sendai 980-8577, Japan.

E-mail: panliu@wpi-aimr.tohoku.ac.jp

or Dr Professor H Zhou, Energy Technology Research Institute, National Institute of Advanced industrial Science and Technology (AIST), Tsukuba 305-8568, Japan.

E-mail: hs.zhou@aist.go.jp

Received 10 December 2015; revised 2 February 2016; accepted 19 February 2016 


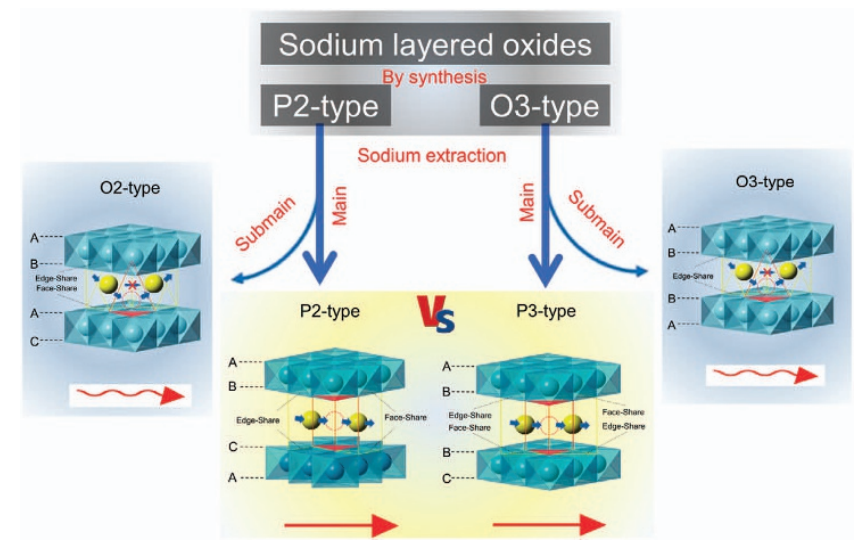

Figure 1 The classification of the layered sodium oxide $\left(\mathrm{Na}_{x} \mathrm{MeO}_{2}\right)$, electrochemical phase transition induced by sodium extraction and $\mathrm{Na}$-ion migration paths in different layered structures. Note that the P2 phase more easily maintains its original structure, and the 03 phase always transforms to the P3 phase during the sodium intercalation process. The yellow and blue balls represent the sodium and transition-metal atoms, respectively. The red circles and shaded parts indicate the intermediate site during sodium diffusion and the interspace between the two sites, respectively. The red lines below show the direct Na migration for the P2 and P3 phases, and the indirect migration for the $\mathrm{O} 2$ and 03 phases.

established. As shown in the bottom of Figure 1, the local environment of the $\mathrm{Na}$ ions at prismatic sites in the $\mathrm{P} 2$ and $\mathrm{P} 3$ phases along with the diffusion pathway are markedly different that immediately determines their respective electrochemical kinetics. No research has been done on the Na-ion conduction of the P3 phase as electrode materials until now, partly because the P3 phase is rarely directly synthesized. ${ }^{27,28}$ Furthermore, the phase transition and relative electrochemical properties are very dependent on the sodium content; ${ }^{29,30}$ therefore, a couple consisting of the P2 and P3 phases having nearly the same compositions is quite essential for conducting this study. Some fundamental issues still need clarification. For instance, what is the best choice between P2 and P3 phases for high-performance electrode materials? How can we understand their structure-properties relationship more clearly?

In this work, we present layered $\mathrm{P} 2-\mathrm{Na}_{0.62} \mathrm{Cr}_{0.63} \mathrm{Ti}_{0.37} \mathrm{O}_{2}$ and $\mathrm{P} 3-\mathrm{Na}_{0.63} \mathrm{Cr}_{0.63} \mathrm{Ti}_{0.37} \mathrm{O}_{2}$ with nearly the same compositions and excellent structural stability, enabling the systematic study of the crystal-structure and electrochemical-property relationships. The electrochemical tests illustrate that the $\mathrm{P} 2$ phase shows a more evident plateau at $0.73 \mathrm{~V}$, lower than that of the P3 phase, and it has a reversible capacity of $110 \mathrm{mAh} \mathrm{g}^{-1}$, higher than that of $\mathrm{P} 3$. With a rate of $10 \mathrm{C}$, the $\mathrm{P} 2$ phase still delivers a large capacity $\left(66 \mathrm{mAh} \mathrm{g}^{-1}\right)$ that is $56 \%$ of the capacity at a rate of $0.2 \mathrm{C}$. After 1000 cycles at a $5 \mathrm{C}$ rate, the capacity retention is $77.5 \%$. The superior rate capability and excellent cycling performances far surpass those of the $\mathrm{P} 3$ phase and even those of other sodium anode materials. ${ }^{31-34} \mathrm{P} 2-\mathrm{Na}_{0.62} \mathrm{Ti}_{0.37} \mathrm{Cr}_{0.63} \mathrm{O}_{2}$, with its usable discharge capacity, safe potential and outstanding rate capability and cycling performance, is a promising candidate for long-life and high-rate sodium-ion batteries. The crystal structures and the charge compensation mechanisms in the layered P2 and P3 structures are first confirmed by atomic-scale characterizations based on spherical aberration-corrected electron microscopy. Most importantly, the first-principles calculation is commonly used to identify a smoother diffusion of $\mathrm{Na}$ in the $\mathrm{P} 2$ phase compared with the diffusion in the $\mathrm{P} 3$ phase. The P2 phase shows a lower sodium diffusion barrier than P3 for sodium multi-vacancies, and it is essentially revealed that the $\mathrm{Na}$ diffusion kinetics are mainly determined by the structural difference (P2 vs P3). The superiority of P2 sodium storage is independent of the transition metal ions, a characteristic that can also be applied to other P-type layered oxides. These insights create a deeper understanding of the crystal structure-electrochemical performance relationship and also provide new avenues for designing advanced electrode materials for sodium-ion batteries.

\section{MATERIALS AND METHODS Material preparation}

The P2- and P3-NTCO raw materials were synthesized via a traditional solidstate reaction. All solid chemical compounds were purchased from Wako Pure Chemicals Industries Ltd (Osaka, Japan). The $\mathrm{Na}_{2} \mathrm{CO}_{3}, \mathrm{Cr}_{2} \mathrm{O}_{3}$ and $\mathrm{TiO}_{2}$ (anatase form) precursors with the same stoichiometric proportion were well ground in an agate mortar at a rotation rate of $200 \mathrm{r} \mathrm{min}^{-1}$ for $20 \mathrm{~h}$. Owing to the volatility of sodium at high temperatures, an excess $5 \mathrm{wt} \%$ of $\mathrm{Na}_{2} \mathrm{CO}_{3}$ was added. The mixture was dried for $12 \mathrm{~h}$ at $100{ }^{\circ} \mathrm{C}$. The obtained powders were pressed into pellets, and then the pellets were heat treated in Ar flow. P3-NTCO was synthesized at a temperature of $900{ }^{\circ} \mathrm{C}$ for $20 \mathrm{~h}$. P2-NTCO was obtained when heat treatment temperature and duration were set to $1000^{\circ} \mathrm{C}$ and $20 \mathrm{~h}$, respectively. A P2 and P3 mixed composite was also obtained at $950{ }^{\circ} \mathrm{C}$ and $20 \mathrm{~h}$. The heated pellets were quenched to room temperature and stored in an argon-filled glove box until use. The molar ratios of the metal ions in the layered P2 and P3 samples were chemically analyzed by inductively coupled plasma mass spectrometry, and the $\mathrm{Na} / \mathrm{Ti} / \mathrm{Cr}$ ratios were determined to be 0.62:0.37:0.63 and 0.63:0.37:0.63, respectively, that matched well with our designed materials.

\section{Characterizations}

The X-ray diffraction (XRD) patterns were performed using $\mathrm{Cu}-\mathrm{K} \alpha$ radiation on a Bruker D8 Advance Diffractometer (Karlsruhe, Germany). A JEOL-2100F STEM (Tokyo, Japan) equipped with a double aberration corrector for both probe-forming and imaging lenses was used to perform high-angle annular dark-field (HAADF) and annular bright-field (ABF) imaging and was operated at $200 \mathrm{KV}$. The convergence angle was $25 \mathrm{mrad}$, and the angular range of collected electrons for HAADF imaging was $\sim 60-250 \mathrm{mrad}$. The discharged electrodes scratched off from the electrodes of the sodium half-cells were subjected to ex situ XRD on a Bruker D8 Advance Diffractometer.

\section{Electrochemistry}

The electrochemical tests were carried out using CR2032 coin-type cells consisting of a working electrode and a $\mathrm{Na}$ counter electrode. The working electrodes were prepared with a weight ratio of $75 \%$ active material, $20 \%$ teflonized acetylene black and 5\% polytetrafluoroethylene. Pellets for half-cells were pressed into the form of aluminum screens $\sim 3 \mathrm{mg}$ in mass and $7 \mathrm{~mm}$ in diameter (the loading mass was $\sim 1.95 \mathrm{mg} \mathrm{cm}^{-2}$ ) and then dried under vacuum at $\sim 110^{\circ} \mathrm{C}$ for $5 \mathrm{~h}$ before assembling the cells. The cells were assembled in a glove box filled with dried argon gas. The electrolyte was $1 \mathrm{~mol} \mathrm{dm}^{-3} \mathrm{NaClO}_{4}$ dissolved in propylene carbonate (Tomiyama Pure Chemical Industries, Fukushima, Japan) with 2 vol\% fluorinated ethylene carbonate as an electrolyte additive. A glass fiber was used as the separator of the sodium half-cells. The galvanostatic charge/discharge tests of P2- and P3NTCO/Na half-cells were performed using a Hokuto Denko HJ1001SD8 battery tester (Tokyo, Japan) at different current densities within a cutoff voltage window of $0.15-2.5 \mathrm{~V}$ vs $\mathrm{Na} / \mathrm{Na}^{+}$at $25^{\circ} \mathrm{C}$ after a $12 \mathrm{~h}$ rest. $1 \mathrm{C}$ corresponds to $100 \mathrm{~mA} \mathrm{~g}^{-1}$ in the cell tests.

\section{First-principles calculation}

Spin-polarized calculations were performed using the Vienna Ab-initio Simulation Package (VASP) $)^{35,36}$ within the projector augmented wave approach. ${ }^{37}$ Generalized gradient approximation in the parameterization of the PBE (Perdew-Burke-Ernzerhof) ${ }^{38}$ pseudopotential was used to describe the exchange-correlation potential. The minimum energy pathways and saddle points of the $\mathrm{Na}^{+}$migration were calculated with the nudged elastic band method. ${ }^{39}$ This approach duplicates a series of images between the starting 
point and the ending point of a diffusing ion to simulate the intermediate states with the positions of the starting point and the end point fixed. The supercell comprises $3 \times 3 \times 1$ conventional unit cells, corresponding to 18 and 27 formula units for the P2 and P3 phases, respectively. The single or multiple vacancy models were constructed by removing one or more $\mathrm{Na}$ ions in the same $\mathrm{Na}$ layer. For the case of multiple $\mathrm{Na}$ vacancy, all possible non-equivalent configurations were calculated, and then the energetically favorable states were adopted for investigating the Na-ion transport behavior. Owing to the large supercell adopted in the nudged elastic band calculations, only the $\Gamma$ point was adopted for $\mathrm{k}$-point sampling to reduce the computational cost. The planewave cutoff was set to $520 \mathrm{eV}$. Geometry optimizations were performed by using conjugate gradient minimization until all the forces acting on the ions were less than $0.01 \mathrm{eV} \AA^{-1}$ per atom.

Galvanostatic intermittent titration technique (GITT) test

The chemical diffusion coefficient of $\mathrm{Na}^{+}\left(D_{\mathrm{Na}}\right)$ is calculated according to Equation (1) and its simplified form Equation (2) derived by Weppner and Huggins $^{40}$ as follows: ${ }^{41}$

$$
\begin{aligned}
& D_{\mathrm{Na}}=\frac{4}{\pi}\left(\frac{m_{\mathrm{B}} V_{\mathrm{M}}}{M_{\mathrm{B}} S}\right)^{2}\left(\frac{E_{\mathrm{s}}}{\left(d E_{\tau} / d \sqrt{\tau}\right)}\right)^{2}\left(\tau<<L^{2}\right) \\
& D_{\mathrm{Na}}=\frac{4}{\pi}\left(\frac{m_{\mathrm{B}} V_{\mathrm{M}}}{M_{\mathrm{B}} S}\right)^{2}\left(\frac{E_{\mathrm{s}}}{\Delta E_{\tau}}\right)^{2}
\end{aligned}
$$

where $V_{\mathrm{M}}$ is the molar volume of the compound, and $M_{\mathrm{B}}$ and $m_{\mathrm{B}}$ are the molecular weight and the mass of the active materials, respectively; $S$ is the interface area between the active material and the electrolyte and $L$ is radius of the active particle.

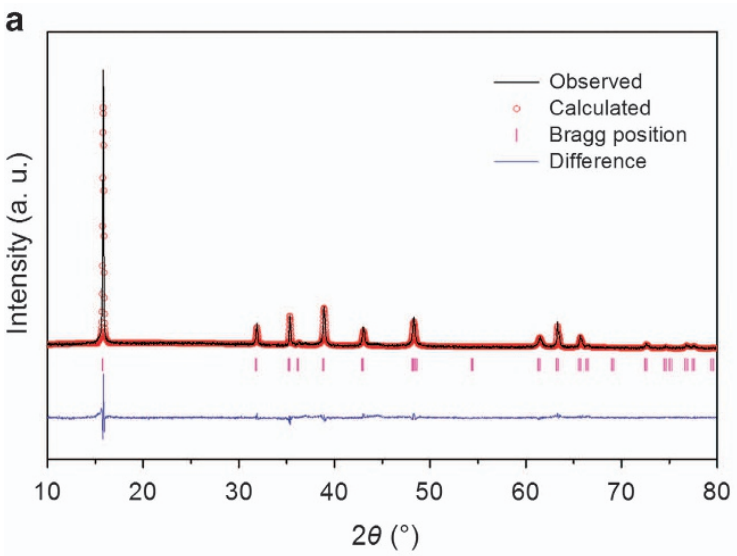

b
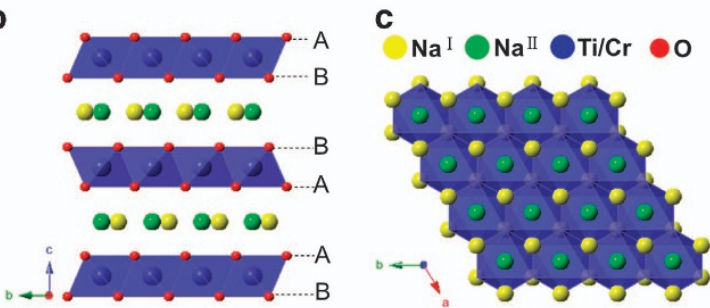

\section{RESULTS}

\section{Structural characterization}

The crystal structures of the samples annealed at different temperatures $\left(900,950\right.$ and $\left.1000^{\circ} \mathrm{C}\right)$ for $20 \mathrm{~h}$ were recorded by XRD in Supplementary Figure S1. These materials show the different crystal structures: P3 structure synthesized at $900{ }^{\circ} \mathrm{C}, \mathrm{P} 2$ structure at $1000^{\circ} \mathrm{C}$ and the mixture of $\mathrm{P} 2$ and $\mathrm{P} 3$ at $950^{\circ} \mathrm{C}$. An overlapping of the $(00 \mathrm{l})$ reflections can be observed for the layered P-type phases in Supplementary Figure S1. It has been demonstrated that a P3-P2 phase transition could be achieved in high-temperature conditions rather than through an electrochemical reaction because of the high energy required to break/reform the $\mathrm{Me}-\mathrm{O}$ bonds for this transformation. ${ }^{26}$ The $\mathrm{P} 2$ and $\mathrm{P} 3$ phases display almost the same composition ( $\mathrm{P} 2-\mathrm{Na}_{0.62} \mathrm{Ti}_{0.37} \mathrm{Cr}_{0.63} \mathrm{O}_{2}$ and $\mathrm{P} 3-\mathrm{Na}_{0.62} \mathrm{Ti}_{0.37} \mathrm{Cr}_{0.63} \mathrm{O}_{2}$ ), hereafter denoted as $\mathrm{P} 2-\mathrm{NTCO}$ and $\mathrm{P} 3-\mathrm{NTCO}$, respectively. Note that the simultaneous synthesis of the layered P2 and P3 phases with the same stoichiometries is the key to making a fair comparison, and this is quite rare to the best of our knowledge.

Figure $2 \mathrm{a}$ shows the Rietveld plots of P2-NTCO, and all the diffraction lines are indexed to a hexagonal lattice with space group $\mathrm{P} 6_{3} / m m c$. The lattice parameters are refined to be $a=b=2.9410$ (1) $\AA$, $c=11.2639(3) \AA$ and $\mathrm{V}=84.375(4) \AA^{3}$ with a convergence factor $\mathrm{R}_{\mathrm{wp}^{-}}$ factor $(9.55 \%)$ and $\chi^{2}(2.210)$ value using GSAS+EXPGUI suite ${ }^{42,43}$ (detailed crystallographic data on refined P2-NTCO are listed in Supplementary Table S1). The crystal structures of P2-NTCO are displayed in Figures $2 \mathrm{~b}$ and $\mathrm{c}$, characterized by ABBA oxygen stacking including two $\mathrm{MeO}_{6}$ octahedra per unit cell (Figure 2b) and offer two
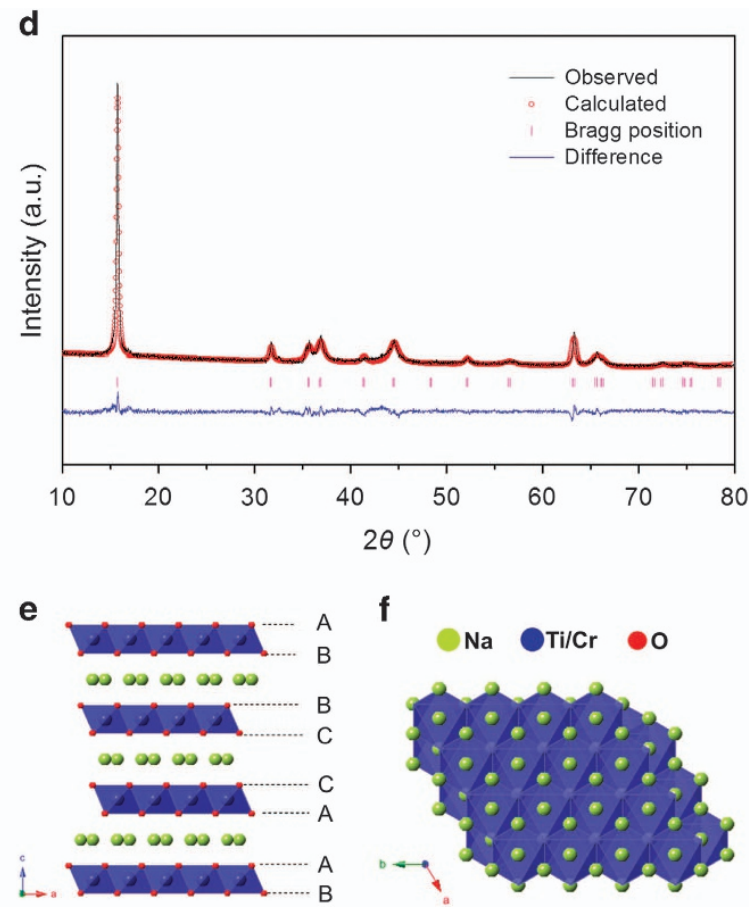

Figure 2 The structure of the P-type NTCO $\left(\mathrm{Na}_{0.62} \mathrm{Ti}_{0.37} \mathrm{Cr}_{0.63} \mathrm{O}_{2}\right)$ materials. (a) The X-ray diffraction (XRD) and Rietveld plots are shown for the P2-NTCO compounds with the experimental data in black dots, the calculated curves in red and the difference curve in blue; the standard Bragg reflections are shown as pink short vertical bars. (b) The P2-type crystal structure viewed along the a axis shows the two different Na-ion sites in green and yellow. (c) The P2-type crystal structure viewed along $\mathrm{C}$ axis shows that every $\mathrm{Na}$ (edge-sharing) site is surrounded by three $\mathrm{Na}$ "ll (face-sharing) sites, and every $\mathrm{Na}$ "l site is surrounded by three Nal sites. (d) The XRD and Rietveld plots are shown for refined P3-NTCO with the experimental data in black dots, the calculated curves in red and the difference curve in blue; the standard Bragg reflections are shown as pink short vertical bars. (e) The P3-type crystal structure viewed along the a axis shows only one type of Na-ion site in the green-yellow color. (f) The P3-type crystal structure is viewed along the $\mathrm{c}$ axis showing that every Na site is edgesharing at one side and face-sharing at the other side. Note that a part of the sodium prisms is open to show the short distances between the sodium sites that cannot be occupied simultaneously. 
different sites for $\mathrm{Na}$ cations, either sharing faces with two $\mathrm{MeO}_{6}$ octahedra of adjacent slabs or sharing edges with six $\mathrm{MeO}_{6}$ octahedra (Figure 2c). The XRD and Rietveld plots of P3-NTCO are shown in Figure $2 \mathrm{~d}$, indicating that all of the diffraction lines can be assigned to the P3-type structure with space group $R \overline{3} \mathrm{~m}$. The Rietveld refinement of the XRD pattern successfully produced reasonably a low $\mathrm{R}_{\mathrm{wp}}$-factor $(8.75 \%)$ and $\chi^{2}$ (1.623) value based on P3 models. The P3 phase was fitted for the lattice parameters of $a=b=2.9466(2) \AA, c=16.8758$ (11) $\AA$ and $V=127.652(19) \AA^{3}$. The calculated XRD patterns of P3 were in good agreement with the experimental data, and the detailed refinement results are also shown in Supplementary Table S1. Figures $2 \mathrm{e}$ and $\mathrm{f}$ also show the crystal structure of P3-NTCO with ABBCCA oxygen stacking, and three $\mathrm{MeO}_{2}$ sheets per unit cell (Figure 2e) had prisms sharing one face with one $\mathrm{MeO}_{6}$ octahedron and three edges with $\mathrm{MeO}_{6}$ octahedra of the next layer, resulting in only one sodium site (Figure 2f). Supplementary Figure S2 displays the scanning electron microscope images of P2- and P3-NTCO samples, and it can be seen that the primary particles of P2- and P3-NTCO without post-treatment were mainly distributed in the same range of $0.5-1.5 \mu \mathrm{m}$. The similar particle distribution of the P2- and P3-NTCO samples ensures a fair comparison of the two different structures.

To further determine the atomistic crystal structures of the P2- and P3-NTCO materials, advanced spherical aberration-corrected electron microscopy experiments were performed at the atomic scale, shown in Figure 3. Figures $3 \mathrm{a}$ and $\mathrm{b}$ indicate the experimental and simulated selected area electron diffraction patterns of the P2 phase, respectively. The bright spots of the P2 phase projected along the [010] direction in Figure 3a corresponds to a typical diffraction pattern for a P2 structure lattice that perfectly matches the simulated stacking sequences along the b-axis crystallographic direction in Figure $3 \mathrm{~b}$. The local structure of the P2-NTCO materials was analyzed with atomic resolution via HAADF and ABF-scanning transmission electron microscopy (STEM). The bright-dot contrast in the HAADF-STEM images (Figure $3 \mathrm{c}$ ) and the dark-dot contrast in the ABF-STEM images (Figure 3d) reveal the transition-metal ( $\mathrm{Ti}$ and $\mathrm{Cr}$ ) atom column positions. The corresponding fast Fourier transform in Figure $3 \mathrm{c}$ is consistent with the selected area electron diffraction pattern. The relatively weak dark-dot localized between the interlayers in the ABFSTEM images (Figure 3d) corresponds to the sodium and oxygen atom columns. Figures $3 \mathrm{e}$ and $\mathrm{f}$ indicate the experimental and simulated selected area electron diffraction patterns of P3 phase. The bright spots projected along the [010] direction in Figure $3 \mathrm{e}$ can be assigned to characteristic reflections originating from the P3 structure lattices, consistent with the simulated results in Figure $3 \mathrm{f}$. The HAADF and ABF-STEM images are also shown in Figures $3 g$ and $h$. The corresponding fast Fourier transform is inserted in Figure $3 \mathrm{~g}$.
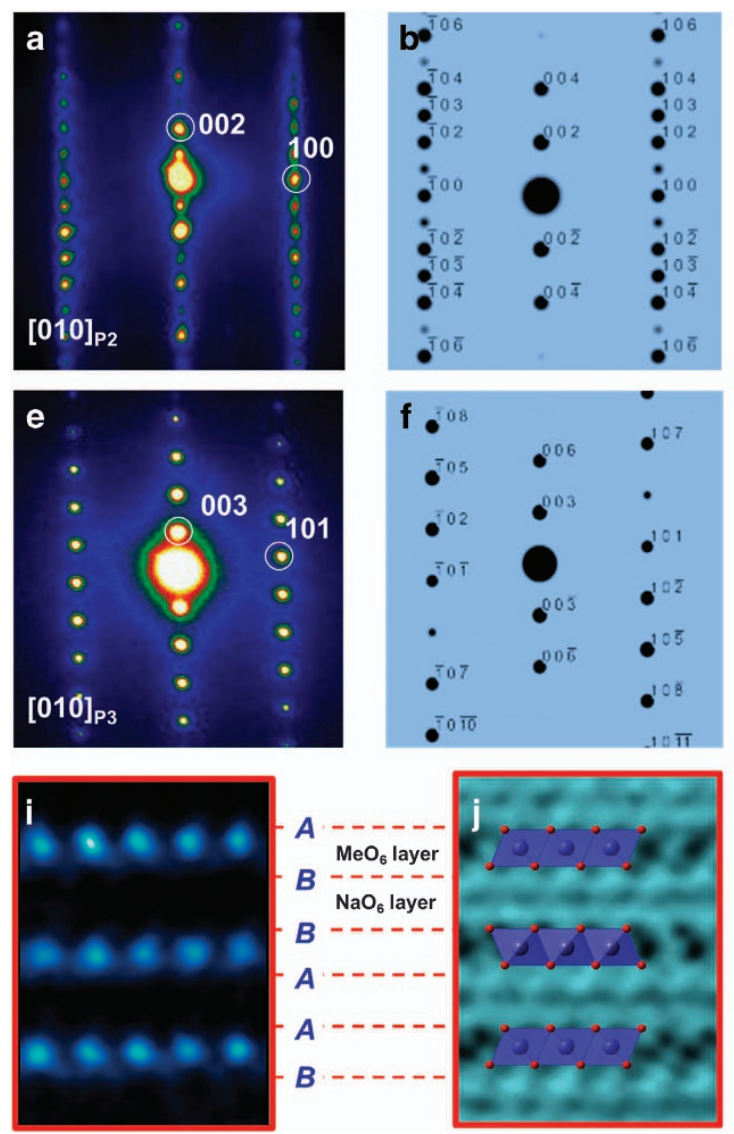
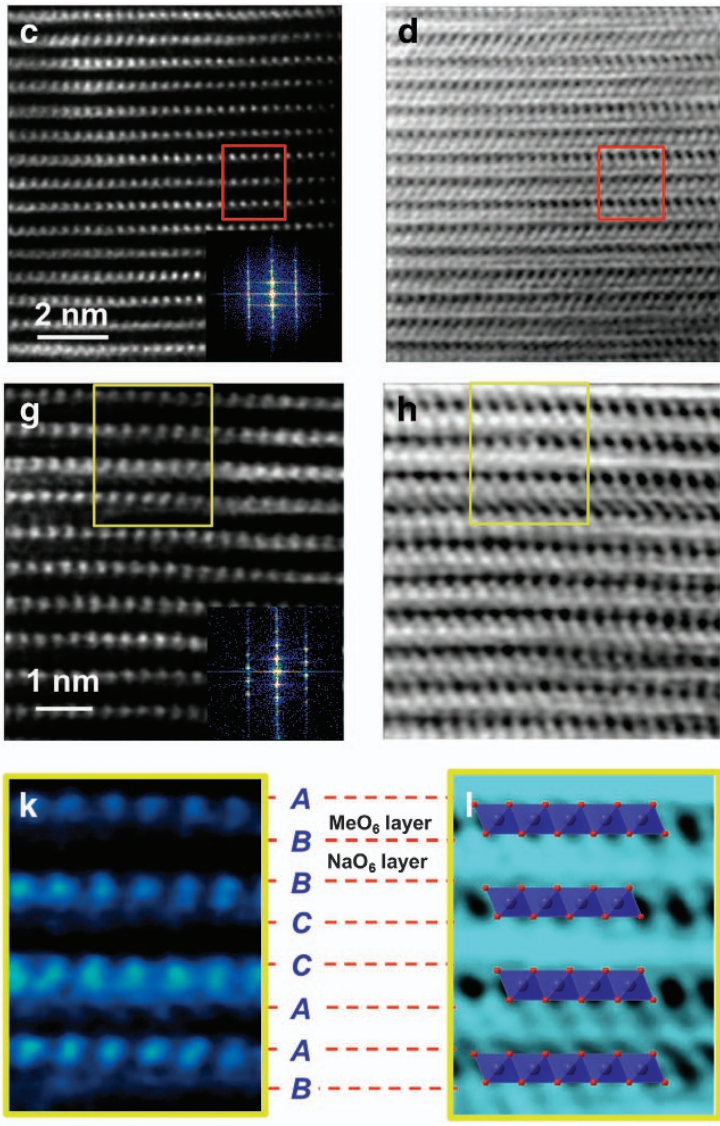

Figure 3 Scanning transmission electron microscopy (STEM) imaging of P-type NTCO $\left(\mathrm{Na}_{0.62} \mathrm{Ti}_{0.37} \mathrm{Cr}_{0.63} \mathrm{O}_{2}\right)$ materials. (a) The experimental selected area electron diffraction (SAED) patterns of P2-NTCO viewed along the [010] zone axis and (b) the simulated SAED patterns of P2-NTCO viewed along the [010] direction. (c) The high-angle annular dark-field (HAADF)-STEM image of P2-NTCO and (d) the annular bright-field (ABF)-STEM image of P2-NTCO. (e) The experimental SAED patterns of P3-NTCO viewed along the [010] zone axis and (f) the simulated SAED patterns of P3-NTCO viewed along the [010] direction. (g) The HAADF-STEM image of P3-NTCO and (h) the ABF-STEM image of P2-NTCO. Images (i) and (j) are enlarged ABF-STEM images extracted from (c) and (d), showing the ABBAAB stacking of P2. Images (k) and (I) are enlarged ABF-STEM images extracted from (g) and (h), showing the ABBCCAAB stacking of P2. 
To directly compare the crystal structures of P2- and P3-NTCO, their enlarged ABF- and HAADF-STEM images are shown in Figures 3i-l. In Figure 3j, the enlarged HAADF-STEM image from Figure $3 \mathrm{~d}$, the detailed atomic arrangements are shown and exhibit a stacking sequence of ABBA, characterizing the layered P2 phase. The atomic model of the layered P2 phase is inserted for convenient visualization. The ABF-STEM observations of octahedral $\mathrm{MeO}_{2}(\mathrm{Me}=$ $\mathrm{Ti}$ and $\mathrm{Cr}$ ) are highly consistent with the structural model, as highlighted by the blue shading in Figure 3j. The alkali metal atoms are held by the $\mathrm{MeO}_{2}$ layers. Specifically, every two layers of $\mathrm{MeO}_{2}$ are structurally a symmetric mirror image for the P2 phase. The enlarged ABF-STEM image in Figure 31 extracted from Figure $3 g$ exhibits the detailed atomic arrangements with regard to the ABBCCA stacking sequence of the layered P3 phase, and the atomic model of the layered P3 structures is also inserted for easy comparison. Furthermore, Supplementary Figures S3a and b show the chemical composition of the pristine P2 and P3 phases via electron energy loss spectroscopy (EELS) mapping, indicating that the $\mathrm{Na}, \mathrm{Ti}, \mathrm{Cr}$ and $\mathrm{O}$ elements are uniformly distributed in material particles.

\section{Sodium storage performance}

The electrochemical properties of P2- and P3-NTCO anode materials are characterized by galvanostatic discharge-charge tests in half-cells with a voltage range of $0.15-2.5 \mathrm{~V}$ at a $0.25 \mathrm{C}$ rate vs $\mathrm{Na}^{+} / \mathrm{Na}$, shown in Figure 4. A reversible discharge capacity of $110 \mathrm{mAh} \mathrm{g}^{-1}$ is obtained for P2-NTCO and $102 \mathrm{mAh} \mathrm{g}^{-1}$ for P3-NTCO in the subsequent cycles at a discharge-charge rate of $0.25 \mathrm{C}$ (Figure $4 \mathrm{a}$ ). The average potentials are also marked in Figure $4 \mathrm{a}$, and $0.73 \mathrm{~V}$ is obtained for $\mathrm{P} 2-\mathrm{NTCO}$ that is lower than that of P3-NTCO $(0.82 \mathrm{~V})$. The typical $\mathrm{dQ} / \mathrm{dV}$ curves of the $\mathrm{P} 2$ and $\mathrm{P} 3$ phases are compared in Supplementary Figure S4, and a couple of sharper redox peaks are associated with the evident plateau-like features in the dischargecharge curves of P2; meanwhile, the P3 phase shows slope-like features in the dQ/dV curves (Supplementary Figure S5). These results indicate that when assembling full cells with the same cathode, the cells using a P2-NTCO as the anode will provide a higher average voltage, larger energy density and better plateau characteristic than those using P3. The discharge-charge profiles of P2- and P3-NTCO in Na half-cells with different rates of $0.25 \mathrm{C}, 0.5 \mathrm{C}, 1 \mathrm{C}, 2.5 \mathrm{C}, 5 \mathrm{C}$ and $10 \mathrm{C}$ are examined and shown in Figure $4 \mathrm{~b}$, and their comparison plots are shown in Figure 4c. At the same C-rate, all of the layered P2 phase samples exhibit a higher discharge capacity than that of the P3 phase. For instance, the layered P2- and P3-NTCO phases deliver a discharge capacity of 99 and $82 \mathrm{mAh} \mathrm{g}^{-1}$ at a 1C rate, respectively. The discharge capacity gap between P2- and P3-NTCO is more remarkable with the rate increase; the discharge capacities are $78 \mathrm{mAh} \mathrm{g}^{-1}$ for $\mathrm{P} 2-\mathrm{NTCO}$ and $54 \mathrm{mAh} \mathrm{g}^{-1}$ for P3-NTCO at 5C rate, and $67 \mathrm{mAh} \mathrm{g}^{-1}$ for P2-NTCO and $38 \mathrm{mAhg}^{-1}$ for P3-NTCO at a 10C rate, respectively. To investigate the capacity contribution of the conductive carbon additive, the electrochemical performance of acetylene black is investigated in Supplementary Figure S6. Many sodium ions can be inserted into acetylene black during the first cycle, and a few sodium ions can be extracted, indicative of an irreversible process and low coulombic efficiency during the first cycle. A reversible capacity of $\sim 30 \mathrm{mAh} \mathrm{g}^{-1}$ can be obtained in the first and subsequent cycles, contributing to a small amount of the electrode capacity. To confirm the solid-electrolyte interphase film of the P2- and P3-NTCO samples, the TEM experiments before and after the discharge process are performed. Supplementary Figures S7a and b are TEM images of the pristine P2- and P3-NTCO samples, where no obvious solidelectrolyte interphase SEI films are observed in the surfaces. After fully discharging up to $0.15 \mathrm{~V}$, the discharged P2- and P3-NTCO samples (Supplementary Figures S7c and d) have a layer of amorphous materials, indicating that the solid-electrolyte interphase films formed after the first sodium insertion, leading to an irreversible capacity during the first cycle. Moreover, the thickness of the solid-electrolyte a

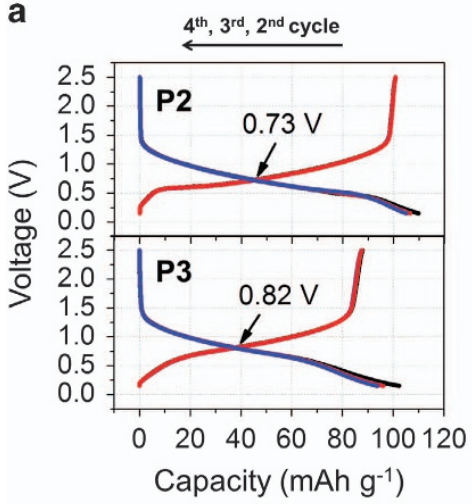

d

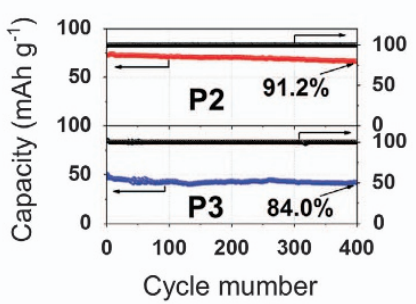

b
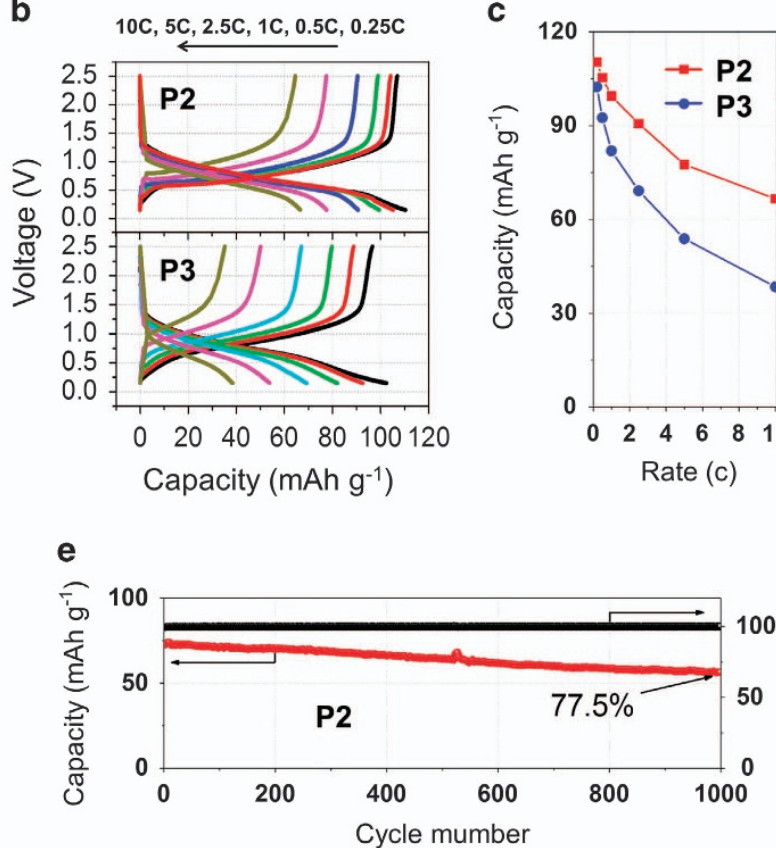

Figure 4 The electrochemical performance of the P2- and P3-NTCO $\left(\mathrm{Na}_{0.62} \mathrm{Ti}_{0.37} \mathrm{Cr}_{0.63} \mathrm{O}_{2}\right)$ compounds. (a) The typical discharge-charge profiles between the 0.15 and $2.5 \mathrm{~V}$ region at a $0.2 \mathrm{C}$ rate $\left(1 \mathrm{C}\right.$ rate corresponding to $100 \mathrm{~mA} \mathrm{~g}^{-1}$ ). (b) The rate capability at different rates of $0.25 \mathrm{C}, 0.5 \mathrm{C}, 1 \mathrm{C}, 2.5 \mathrm{C}, 5 \mathrm{C}$ and 10C. (c) The plots of the reversible capacity versus the $\mathrm{C}$ rates. (d) The cycling performance of 400 cycles with the Coulombic efficiency at a $5 \mathrm{C}$ rate. (e) The cycling performance of 1000 cycles with Coulombic efficiency for only P2-NTCO at a 5C rate. 
interphase films of the discharged P2- and P3-NTCO samples is similar, $\sim 15 \mathrm{~nm}$.

The cycle stability and the coulombic efficiency are evaluated at a rate of 5C in Figure 4d. The capacity of the P2-NTCO after 400 cycles with a $5 \mathrm{C}$ rate remains at $66 \mathrm{mAh} \mathrm{g}^{-1}$, the corresponding capacity retention is $91.2 \%$ and the average coulombic efficiency is close to $100 \%$, demonstrating good electrochemical reversibility. However, the capacity retention of P3-NTCO after 400 cycles with a $5 \mathrm{C}$ rate is only $84.0 \%$. The long-term cycling performance is further studied for P2-NTCO at a higher rate of 5C (Figure 4e). A capacity retention of $77.5 \%$ was measured even after 1000 cycles, and the capacity decay rates only amounted to $\sim 0.0225 \%$ per cycle. The good cycling performance of P2-NTCO is mostly attributed to the enhanced structural stability of the layered $\mathrm{P} 2-\mathrm{Na}_{0.62} \mathrm{Ti}_{0.37} \mathrm{Cr}_{0.63} \mathrm{O}_{2}$ electrode material during sodium ion insertion/extraction processes. Therefore, the appealing electrochemical performance of P2-NTCO, which features an excellent long-term cycle stability and Coulombic efficiency, can prompt the use of rechargeable sodium-ion batteries for large-scale energy-storage devices.

\section{Charge compensation and sodium storage mechanisms}

To further understand the structural and valence evolution of P2- and P3-NTCO during Na insertion, ex situ XRD and EELS experiments are performed. Supplementary Figure S8 shows the ex situ XRD patterns of P2-NTCO and P3-NTCO, closely matching the standard reflection of the P2 and P3 structures, respectively, and there is no evident appearance of a consistent $\mathrm{P} 2-\mathrm{O} 2$ or $\mathrm{P} 3-\mathrm{O} 3$ phase transition upon $\mathrm{Na}$ insertion, potentially indicating the approximate single-phase mechanism. The refinement results are shown in Supplementary Table S2, and the volume change of $\mathrm{P} 2$ is $\sim 0.3 \%$, which is less than that of $\mathrm{P} 3$ $(\sim 0.7 \%)$, revealing that the $\mathrm{P} 2$ phase possesses less lattice strain and better structural stability upon cycling. The minimal volume change in P2 could contribute to long-term cycling with enhanced capacity retention. The stable P-type framework during the electrochemical process has a positive influence on the following Na-ion diffusion study. Figure 5 shows that the atomic resolution STEM-EELS line scanning was performed vertically throughout the c-axis, providing an energy resolution of $0.5 \mathrm{eV}$. The $\mathrm{Ti} \mathrm{L}_{2,3}$ and $\mathrm{Cr} \mathrm{L}_{2,3}$ edges were acquired simultaneously, and a suitable energy dispersion of $0.3 \mathrm{eV}$ per pixel was selected. In this way, the pristine and discharged P2- and P3-NTCO particles (Figures 5a and b) were investigated, respectively. Figure $5 \mathrm{c}$ shows the high-resolution EELS profiles to quantitatively understand the elemental information and valence state of the NTCO system. Remarkably, in the process of discharging the P2 and P3 samples, the critical excitation energy for Ti- $\mathrm{L}_{3}$ shifts to $459.1 \mathrm{eV}$ from the original $461.4 \mathrm{eV}$, and for $\mathrm{Ti}-\mathrm{L}_{2}$, it shifts to $453.9 \mathrm{eV}$ from $456.2 \mathrm{eV}$. For the ELNES of $\mathrm{Ti}_{2,3}$, the major difference in the electron structure of the pristine and discharged Ti element (in P2 or P3 phases) is the degree of occupancy of the $t_{2 g}$ level. $\mathrm{Ti}^{3+}$ has one $t_{2 g}$ electron and $\mathrm{Ti}^{4+}$ has none, and this is very noticeably reflected in the position of the fine $\mathrm{Ti}^{\mathrm{L}} \mathrm{L}_{2,3}$ edges. Thus, the shift of $\mathrm{Ti} \mathrm{L}_{2,3}$ is assigned to the formation of $\mathrm{Ti}^{3+}$ during the discharging process. However, the peak position and energy shift exhibited as well as the ratio of

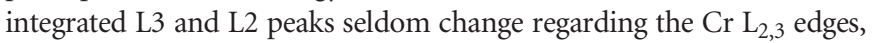

a
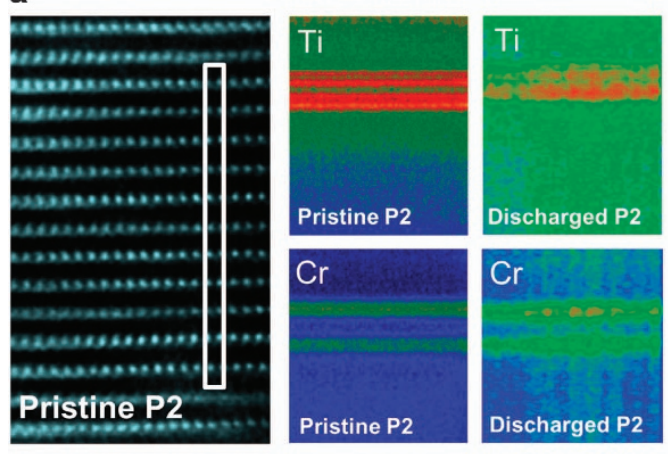

b

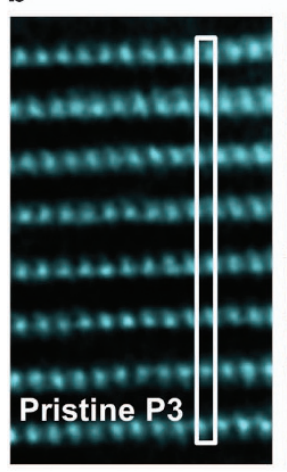

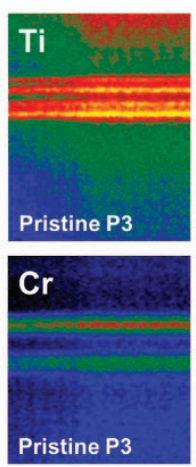

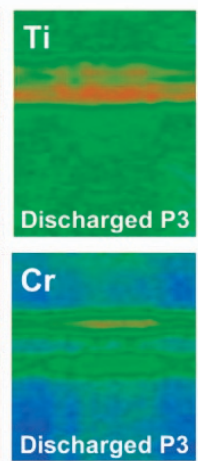

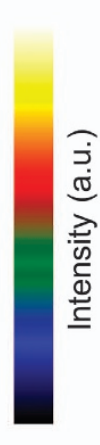

High resolution raw data profiles

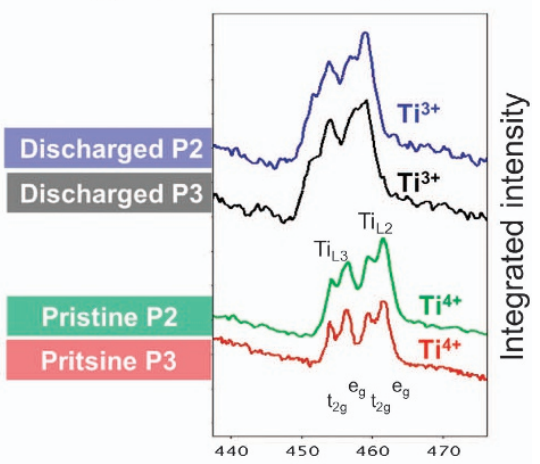

Energy Loss (eV)
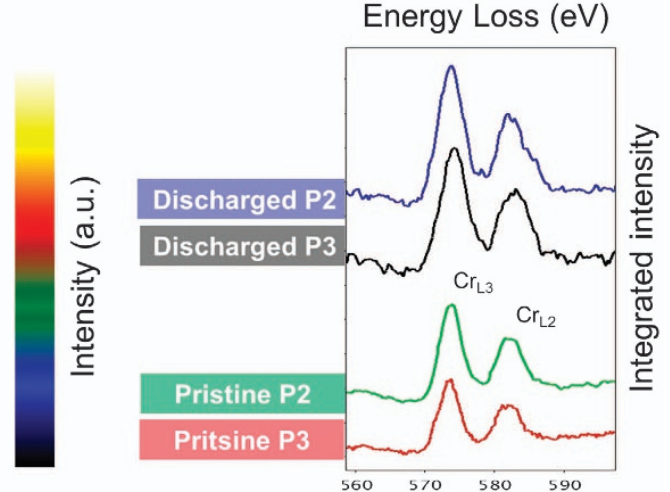

Figure 5 The electron energy loss spectroscopy (EELS) analysis showing the remarkable valence change of titanium in the P2- and P3-NTCO $\left(\mathrm{Na}_{0.62} \mathrm{Ti}_{0.37} \mathrm{Cr}_{0.63} \mathrm{O}_{2}\right)$ compounds. (a) The EELS mapping of pristine P2-NTCO; the white rectangle of the scanning transmission electron microscopy (STEM) image indicates the analysis area. The colorful atomic resolution STEM-EELS line scanning images show $\mathrm{Ti}$ and $\mathrm{Cr}$ along the $\mathrm{c}$ axis before and after discharge. (b) The EELS mapping of pristine P3-NTCO; the white rectangle of the STEM image indicates the analysis area. The colorful atomic resolution STEM-EELS line scanning images show Ti and $\mathrm{Cr}$ along the $\mathrm{c}$ axis before and after discharge. (c) The high-resolution EELS profiles of the P2- and P3-NTCO compounds. 
verifying the invariant $\mathrm{Cr}^{3+}$ during the charge-discharge process. From a conventional atomic physical point of view, transition metal atoms ( $\mathrm{Ti} / \mathrm{Cr}$ ) combined with electronegative atoms (oxygen) or trapped inside an electronegative environment always exhibit a shift in energy, meaning that there is slight overoxidation of the $\mathrm{Ti} / \mathrm{Cr}$ atoms. For these anode materials, only the $\mathrm{Ti} \mathrm{L}_{2,3}$ edge changes significantly, corresponding to the $\mathrm{Ti}^{4+}-\mathrm{Ti}^{3+}$ reduction during $\mathrm{Na}$ insertion.

\section{DISCUSSION}

The phase stability of both the P2 and P3 phases during the electrochemical measurements, as evidenced by the above ex situ $\mathrm{XRD}$ results, allows us to assess the difference between the $\mathrm{Na}$-ion transport of the P2 and P3 phases by employing density functional theory-based first-principles calculations. The EELS data have shown that only Ti redox works during the charge-discharge process, and the $\mathrm{Cr}$ ions are electrochemically inactive. Accordingly, the $\mathrm{P} 2-\mathrm{Na}_{0.62} \mathrm{Ti}_{0.37} \mathrm{Cr}_{0.63} \mathrm{O}_{2}$ and $\mathrm{P} 3-\mathrm{Na}_{0.63} \mathrm{Ti}_{0.37} \mathrm{Cr}_{0.63} \mathrm{O}_{2}$ used in our work are considered to be $\mathrm{Cr}$-substituted $\mathrm{Na}_{0.6} \mathrm{TiO}_{2}$. For convenience, we first study P2- and $\mathrm{P} 3-\mathrm{Na}_{x} \mathrm{TiO}_{2}$. As mentioned earlier, there are two crystallographically distinguishable trigonal prismatic $\mathrm{Na}$ sites in $\mathrm{P} 2-\mathrm{Na}_{x} \mathrm{TiO}_{2}$, denoted by the $\mathrm{Na}^{\mathrm{I}}$ and $\mathrm{Na}^{\mathrm{II}}$ sites (Figures $2 \mathrm{~b}$ and $\mathrm{c}$ ). The $\mathrm{Na}^{\mathrm{I}} \mathrm{O}_{6}$ prism is face-sharing with $\mathrm{TiO}_{6}$ octahedra, and the $\mathrm{Na}^{\mathrm{II}} \mathrm{O}_{6}$ prism is edge-sharing with $\mathrm{TiO}_{6}$ octahedra. In contrast, all $\mathrm{Na}$ sites in the P3 phase are crystallographically equivalent, edge-sharing with $\mathrm{TiO}_{6}$ octahedra at one side and face-sharing with $\mathrm{TiO}_{6}$ octahedron at another side (Figures 2e and $\mathrm{f}$ ). Here, we divide the Na sites of the P3 phase into $\mathrm{Na}^{\mathrm{I}}$ and $\mathrm{Na}^{\mathrm{II}}$, analogous to the $\mathrm{P} 2$ phase. It should be noted that this is an artificial classification for a convenient comparison between the P2 and P3 phases in the following calculations. The computational results show that for stoichiometric $\mathrm{P} 2-\mathrm{NaTiO}_{2}$, all $\mathrm{Na}$ ions occupy the $\mathrm{Na}^{\mathrm{II}}$ sites, consistent with previous computational research on $\mathrm{P} 2-\mathrm{NaCoO}_{2} \cdot{ }^{44}$ For stoichiometric $\mathrm{P} 3-\mathrm{NaTiO}_{2}$, the ground state is such that either the $\mathrm{Na}^{\mathrm{I}}$ or $\mathrm{Na}^{\mathrm{II}}$ sites are fully occupied by $\mathrm{Na}$ ions because $\mathrm{P} 3-\mathrm{Na}^{\mathrm{I}} \mathrm{TiO}_{2}$ and $\mathrm{P} 3-\mathrm{Na}^{\mathrm{II}} \mathrm{TiO}_{2}$ are equivalent. In this work, $\mathrm{P} 3-\mathrm{Na}^{\mathrm{II}} \mathrm{TiO}_{2}$ was used for direct comparison with the $\mathrm{P} 2$ phase.

From the 2D visualization of Na layer in Supplementary Figure S9a, we see that a $\mathrm{Na}^{\mathrm{I}}$ site is a nearest neighbor to three $\mathrm{Na}^{\mathrm{II}}$ sites, and vice versa. Therefore, $\mathrm{Na}$ diffusion in the $\mathrm{Na}$ layer inevitably involves repeating $\mathrm{Na}^{\mathrm{I}} \rightarrow \mathrm{Na}^{\mathrm{II}} \rightarrow \mathrm{Na}^{\mathrm{I}}$ migrations. Under the single vacancy approximation, calculation results show that the activation energy of Na diffusion is much higher in the P2 phase than that in the P3 phase (Supplementary Figures S9c and d). From Supplementary Figure S9b, we can see that the transient state is reached when a $\mathrm{Na}$ ion occupies the $\mathrm{Na}^{\mathrm{I}}$ site, and thus the above results are easy to understand: in the P2 phase, the face-sharing $\mathrm{Na}^{\mathrm{I}}$ site endures more electrostatic repulsion from the $\mathrm{Ti}$ ions, leading to a high energy barrier during the $\mathrm{Na}$-ion diffusion process; for comparison, the $\mathrm{Na}^{\mathrm{I}}$ site is equivalent to the $\mathrm{Na}^{\mathrm{II}}$ site in the $\mathrm{P} 3$ phase, resulting in a lower $\mathrm{Na}$-ion diffusion barrier.

Under the single vacancy approximation, the calculations seem to contradict the experiments, suggesting better $\mathrm{Na}$-ion diffusion kinetics in the P2 phase than in the P3 phase. Nevertheless, for the P-type $\mathrm{Na}_{x} \mathrm{MeO}_{2} \quad(\mathrm{Me}=3 \mathrm{~d}$ transition metal), the $\mathrm{Na}$ content $x$ is $<1.0$ $(0.6<x<1.0$ in our case); therefore, $\mathrm{Na}$ vacancy clusters are always expected in practical electrode materials. Next, we tried to study the $\mathrm{Na}$ diffusion behavior in the presence of more vacancies. The divacancy model is constructed by removing two adjacent $\mathrm{Na}$ ions from $\mathrm{Na}^{\mathrm{II}}$ site, as shown in Supplementary Figure S10a. After relaxation, the $\mathrm{Na}$ ion nearest the divacancy migrate from the $\mathrm{Na}^{\mathrm{II}}$ site to the $\mathrm{Na}^{\mathrm{I}}$ site between the two vacancies (Supplementary Figure S10b). This spontaneous migration is consistent with a previous report, indicating that the $\mathrm{Na}$ ion starts to occupy the $\mathrm{Na}^{\mathrm{I}}$ site when more than one Na vacancy is formed. Moreover, we find no stable a

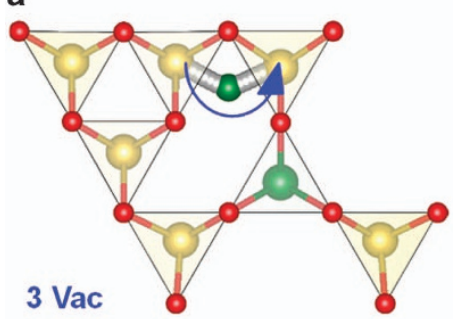

b
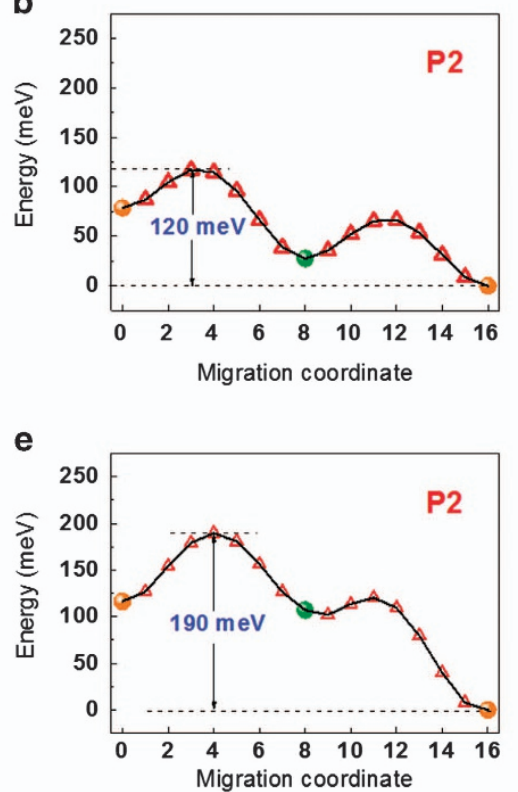

C

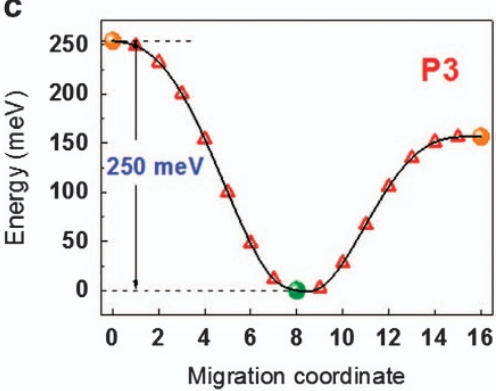

f

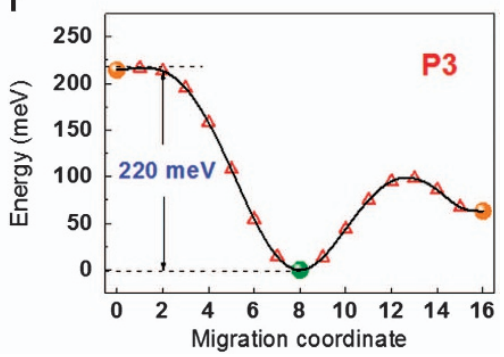

Figure 6 The calculated energy barriers and trajectories of $\mathrm{Na}$-ion diffusion in P2- and P3- $\mathrm{NaTiO}_{2}$. (a) A schematic of the Na-ion diffusion path in layered P-type structures in the case of three $\mathrm{Na}$ vacancies. The $\mathrm{Na}^{\prime} \mathrm{O}_{6}$ and $\mathrm{Na}^{\prime \prime} \mathrm{O}_{6}$ prisms are represented by the green and yellow colors, respectively. (b) The Naion diffusion barrier of the P2-type phase under the condition of three $\mathrm{Na}$ vacancies. (c) The Na-ion diffusion barrier of the P3-type phase under the condition of three Na vacancies. (d) A schematic of the Na-ion diffusion path in layered P-type structures in the case of four Na vacancies. (e) The Na-ion diffusion barrier of the P2-type phase under the condition of three Na vacancies. (f) The Na-ion diffusion barrier of the P3-type phase under the condition of three Na vacancies. 
configuration other than that shown in Supplementary Figure S10b, suggesting that all $\mathrm{Na}$ ions are fixed in the case of divacancy, and more vacancies are necessary for $\mathrm{Na}$-ion diffusion.

Based on the above 'rigid' divacancy model, we created more $\mathrm{Na}$ vacancies to study the Na-ion diffusion process in the presence of a $\mathrm{Na}^{\mathrm{I}}$ ion. For the three vacancies condition (Figure 6a), the energy barrier of the Na-ion migration from one $\mathrm{Na}^{\mathrm{II}}$ site to another in the $\mathrm{P} 2$ phase is calculated to be $120 \mathrm{meV}$ (Figure 6b) that is not only far below the single vacancy case but also lower than that of the three vacancies condition in the P3 phase (Figure 6c). In the case of four vacancies (Figure 6d), the Na-ion migration barrier is calculated to be 190 and $220 \mathrm{meV}$ for the P2 and P3 phases, respectively (Figures 6e and $\mathrm{f})$. After introducing the $\mathrm{Cr}$ element into $\mathrm{Ti}$ sites $\left(\mathrm{Na}_{x} \mathrm{Ti}_{0.44^{-}}\right.$ $\mathrm{Cr}_{0.56} \mathrm{O}_{2}$ ), the calculation results in Figure 7 show that the Cr-substituted $\mathrm{Na}_{x} \mathrm{TiO}_{2}$ exhibit nearly the same behavior as the pristine $\mathrm{Na}_{x} \mathrm{TiO}_{2}$. That is, the Na-diffusion barrier of the P2 phase is much higher than that of the $\mathrm{P} 3$ phase in the case of a single vacancy; meanwhile, in the presence of multiple vacancies, the $\mathrm{Na}$ diffusion barrier of the P2 phase is largely reduced to a value even lower than that of the $\mathrm{P} 3$ phase. The above results suggest that the $\mathrm{Na}$ diffusion kinetics are mainly determined by a structural difference (P2 vs P3) rather than by the type of transition metal ions ( $\mathrm{Ti}$ or $\mathrm{Cr}$ ). Therefore, we focus on the structural difference between the P2 and P3 structures in the following discussions.

By analyzing the above calculation results, we see that the energy barrier of the Na-ion diffusion is largely determined by the energy differences between the $\mathrm{Na}^{\mathrm{I}}$ and $\mathrm{Na}^{\mathrm{II}}$ sites. The site energy difference can approximately be attributed to the intralayer $\mathrm{Na}$ interaction and the transition metal ( $\mathrm{Ti}$ or $\mathrm{Cr}$ ) repulsion. We qualitatively show the effects of the two main factors on the $\mathrm{Na}^{\mathrm{I}}$ site energy (relative to the $\mathrm{Na}^{\mathrm{II}}$ site) in Supplementary Table S3. Notably, the values provided in Supplementary Table S3 are approximations, and the energy barrier of the ionic diffusion results from complex interactions between the diffusion ions and the surrounding crystal lattice. Under the single vacancy approximation, the intralayer Na-ion interactions (in both the $\mathrm{P} 2$ and $\mathrm{P} 3$ phases) cause an increase of ca. $0.2 \mathrm{eV}$ in the energy of the $\mathrm{Na}^{\mathrm{I}}$ sites (relative to that of the $\mathrm{Na}^{\mathrm{II}}$ sites), denoted by an up arrow. The transition metal repulsion, however, differs in the two phases. For the P2 phase, as we have mentioned earlier, the $\mathrm{Na}^{\mathrm{I}}$ ion endures a much higher electrostatic repulsion from the transition metal ions (ca. $0.3 \mathrm{eV}$ ), greatly increasing the $\mathrm{Na}^{\mathrm{I}}$ site energy (to ca. $0.5 \mathrm{eV}$ ); meanwhile, in the $\mathrm{P} 3$ phase, the $\mathrm{Na}^{\mathrm{I}}$ ion gains no more energy from the transition metal repulsion compared with the $\mathrm{Na}^{\mathrm{II}}$ ion, and

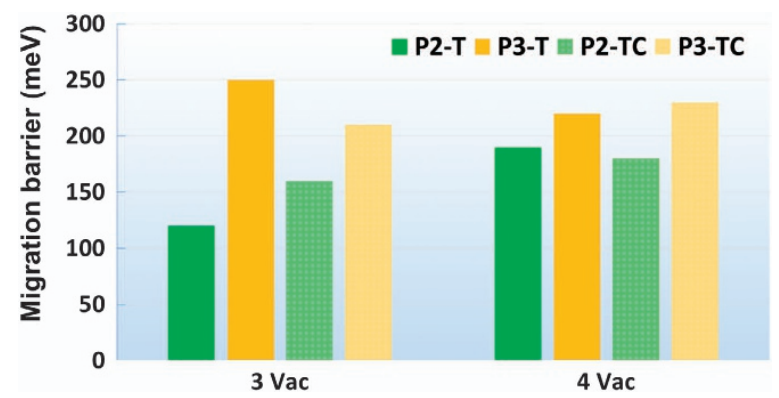

Figure 7 The calculated energy barrier of the Na-ion diffusion process for the following types: three vacancies ( $3 \mathrm{Vac}$ ) and four vacancies ( $4 \mathrm{Vac}$ ), and in $\mathrm{NaTiO}_{2}$ (solid bars) and $\mathrm{NaTi}_{0.44} \mathrm{Cr}_{0.56} \mathrm{O}_{2}$ (shaded bars) with layered P2 (green) and P3 (orange) structures, suggesting that the $\mathrm{Na}$ diffusion kinetics are determined by a structural difference (P2 vs P3) and independent of the transition metal ions. therefore the relative energy of the $\mathrm{Na}^{\mathrm{I}}$ site is solely determined by the intralayer $\mathrm{Na}$-ion interactions, leading to a much lower energy barrier.

In the case of more $\mathrm{Na}$ vacancies, the essential difference observed from the single vacancy approximation lies in the occupation of the $\mathrm{Na}^{\mathrm{I}}$ site. The occupied $\mathrm{Na}^{\mathrm{I}}$ site reduces the site energy of its adjacent $\mathrm{Na}^{\mathrm{I}}$ site (ca. $-0.2 \mathrm{eV}$ ), making the $\mathrm{Na}^{\mathrm{I}}$ site more energetically favorable than the $\mathrm{Na}^{\mathrm{II}}$ site. Therefore, the intralayer Na-ion interaction of more $\mathrm{Na}$ vacancy cases is represented by a down arrow in Supplementary Table S3. Because the transition metal repulsion has no contribution to the relative energy of the $\mathrm{Na}^{\mathrm{I}}$ site in the $\mathrm{P} 3$ phase, we can see from Figures $6 \mathrm{c}$ and $\mathrm{f}$ that the $\mathrm{Na}$ ion reaches an energy minimum at the $\mathrm{Na}^{\mathrm{I}}$ site. For the $\mathrm{P} 2$ phase, however, the transition metal repulsion tends to increase the relative energy of the $\mathrm{Na}^{\mathrm{I}}$ site (ca. $0.3 \mathrm{eV}$ ), thereby counterbalancing the intralayer $\mathrm{Na}$-ion interaction to some extent, resulting in a low activation energy barrier for $\mathrm{Na}$-ion diffusion (ca. $0.1 \mathrm{eV}$ ). In aggregate, the mobility of the $\mathrm{Na}$ ions in the P2 phase are greatly promoted given the presence of multiple vacancies, further demonstrating the excellent electrochemical performance of the P2-NTCO electrode.

In addition to the first-principles calculation, the GITT was also experimentally performed to compare the Na-ion mobilities in the P2 and P3-NTCO materials. Supplementary Figure S11 shows the variation of the chemical diffusion coefficient of Na-ions $\left(D_{\mathrm{Na}}\right)$ determined from the GITT profiles in P2-NTCO and P3-NTCO, respectively. Both the Na-ion diffusion coefficients present a downward trend during the discharge process and a rising trend during the charge process. This variation of sodium ion diffusion during the whole cycling process likely results from an increase or decrease in the sodium content in the crystal structure. The $D_{\mathrm{Na}}$ in P2-NTCO exhibits $1 \times 10^{-12}-2 \times 10^{-13} \mathrm{~cm}^{2} \mathrm{~S}^{-1}$, which is remarkably higher than the corresponding Na diffusivity in P3-NTCO $\left(2 \times 10^{-13}-9 \times\right.$ $\left.10^{-14} \mathrm{~cm}^{2} \mathrm{~S}^{-1}\right)$. Both the calculation results and the GITT measurement demonstrate that $\mathrm{Na}$-ion diffusion in the $\mathrm{P} 2$ phase is faster than that of P3 phase, indirectly evidencing multiple-vacancy Na-ion diffusion in the $\mathrm{P} 2$ phase.

In summary, the polytype $\mathrm{P} 2-\mathrm{Na}_{0.62} \mathrm{Ti}_{0.37} \mathrm{Cr}_{0.63} \mathrm{O}_{2}$ and $\mathrm{P} 3-\mathrm{Na}_{0.63} \mathrm{Ti}_{0.37} \mathrm{Cr}_{0.63} \mathrm{O}_{2}$ with nearly the same compositions and different layered structures were successfully synthesized. Their sodium storage performances were systematically investigated and compared, and the bridge between the crystal structures, migration paths and electrochemical properties was thoroughly outlined for the first time. An excellent rate capability $\left(66 \mathrm{mAh} \mathrm{g}^{-1}\right.$ at a $10 \mathrm{C}$ rate) and cycling performance $(77.5 \%$ capacity retention after 1000 cycles) as well as a safe sodium insertion/extraction potential of $0.73 \mathrm{~V}$ in $\mathrm{P} 2-\mathrm{Na}_{0.62} \mathrm{Ti}_{0.37} \mathrm{Cr}_{0.63} \mathrm{O}_{2}$ suggest that it is a promising anode candidate for sodium-ion batteries for large-scale energy storage. The high safety, suitable voltage, usable capacity and superior cycling performance characteristics make layered titanium-based oxides highly promising anode candidates for practical sodium-ion batteries (Supplementary Table S4). When applied in electrical energy storage such as in a smart grid, the safety and long life are the most critical factors other than capacity. Therefore, the development of new layered titanium-based oxides advances sodium-ion batteries toward large-scale applications. The first-principles calculation was conducted to investigate the essential distinction between the P2 and P3 phase. The density functional theory calculations clearly reveal that the sodium diffusion barrier in the P2 phase is greatly reduced under the condition of multi-vacancies to a value even lower than that of the P3 phase. GITT results also illustrate that the $\mathrm{P} 2$ phase possesses smoother sodium-ion diffusion than the P3 phase. In essence, $\mathrm{Na}$ diffusion kinetics are mainly determined by a structural difference (P2 vs P3) rather than 
the type of transition metal ions ( $\mathrm{Ti}$ or $\mathrm{Cr}$ ). The crystal structuremigration path-electrochemical performance relationship was established in layered P-type structures for the first time, and this work, combining experimental and calculated methods, also provides new avenues for designing advanced electrode materials of sodium-ion batteries.

\section{CONFLICT OF INTEREST}

The authors declare no conflict of interest.

\section{ACKNOWLEDGEMENTS}

PL and MC are sponsored by the JST-CREST 'Phase Interface Science for Highly Efficient Energy Utilization’, JST (Japan).

1 Liu, J., Zhang, J. G., Yang, Z., Lemmon, J. P., Imhoff, C., Graff, G. L., Li, L., Hu, J., Wang, C. \& Xiao, J. Materials science and materials chemistry for large scale electrochemical energy storage: from transportation to electrical grid. Adv. Funct. Mater. 23, 929-946 (2013).

2 Kundu, D., Talaie, E., Duffort, V. \& Nazar, L. F. The emerging chemistry of sodium ion batteries for electrochemical energy storage. Angew. Chem. Int. Ed. 54, 3431-3448 (2015).

3 Kim, S. W., Seo, D. H., Ma, X., Ceder, G. \& Kang, K. Electrode materials for rechargeable sodium-ion batteries: potential alternatives to current lithium-ion batteries. Adv. Energy Mater. 2, 710-721 (2012).

4 Pan, H., Hu, Y.-S. \& Chen, L. Room-temperature stationary sodium-ion batteries for large-scale electric energy storage. Energy Environ. Sci. 6, 2338-2360 (2013)

5 Xiang, X., Zhang, K. \& Chen, J. Recent advances and prospects of cathode materials for sodium-ion batteries. Adv. Mater. 27, 5343-5364 (2015).

$6 \mathrm{Xu}$, J., Lee, D. H. \& Meng, Y. S. Recent advances in sodium intercalation positive electrode materials for sodium ion batteries. Funct. Mater. Lett. 6, 1330001 (2013)

$7 \mathrm{Ma}, \mathrm{C} ., \mathrm{Xu}, \mathrm{J}$., Alvarado, J., Qu, B., Somerville, J., Lee, J. Y. \& Meng, Y. S. Investigatin the energy storage mechanism of SnS2-rGO composite anode for advanced Na-ion batteries. Chem. Mater. 27, 5633-5640 (2015)

$8 \mathrm{Su}, \mathrm{D} .$, Ahn, H.-J. \& Wang, G. $\beta-\mathrm{MnO} 2$ nanorods with exposed tunnel structures as high-performance cathode materials for sodium-ion batteries. NPG Asia Mater. 5 e70 (2013)

9 Su, D. \& Wang, G. Single-crystalline bilayered V205 nanobelts for high-capacity sodium-ion batteries. ACS Nano 7, 11218-11226 (2013).

10 You, Y., Wu, X.-L., Yin, Y.-X. \& Guo, Y.-G. High-quality Prussian blue crystals as superior cathode materials for room-temperature sodium-ion batteries. Energy Environ. Sci.7 1643-1647 (2014).

11 Yan, Y., Yin, Y. X., Guo, Y. G. \& Wan, L. J. A sandwich-like hierarchically porous carbon/graphene composite as a high-performance anode material for sodium-ion batteries. Adv. Energy Mater. 4, 1301584 (2014).

12 Zhou, T., Pang, W. K., Zhang, C., Yang, J., Chen, Z., Liu, H. K. \& Guo, Z. Enhanced sodium-ion battery performance by structural phase transition from two-dimensional hexagonal-SnS2 to orthorhombic-SnS. ACS Nano 8, 8323-8333 (2014).

13 Li, L., Seng, K. H., Li, D., Xia, Y., Liu, H. K. \& Guo, Z. SnSb@ carbon nanocable anchored on graphene sheets for sodium ion batteries. Nano Res. 7 1466-1476 (2014).

$14 \mathrm{Hu}$, Z., Zhu, Z., Cheng, F., Zhang, K., Wang, J., Chen, C. \& Chen, J. Pyrite FeS 2 for high-rate and long-life rechargeable sodium batteries. Energy Environ. Sci. 8 1309-1316 (2015).

15 Wang, S., Wang, L., Zhu, Z., Hu, Z., Zhao, Q. \& Chen, J. All organic sodium-ion batteries with Na4C8H206. Angew. Chem. Ind. Ed. 126, 6002-6006 (2014).

16 Delmas, C., Fouassier, C. \& Hagenmuller, P. Structural classification and properties of the layered oxides. Physica B+C 99, 81-85 (1980).

17 Guo, S., Liu, P., Yu, H., Zhu, Y., Chen, M., Ishida, M. \& Zhou, H. A layered P2- and 03-type composite as a high-energy cathode for rechargeable sodium-ion batteries. Angew. Chem. Int. Ed.127, 5992-5997 (2015).

18 Guo, S., Liu, P., Sun, Y., Zhu, K., Yi, J., Chen, M., Ishida, M. \& Zhou, H. A high-voltage and ultralong-life sodium full cell for stationary energy storage. Angew. Chem. Int. Ed. 54, 11701-11705 (2015)

19 Kim, D., Kang, S. H., Slater, M., Rood, S., Vaughey, J. T., Karan, N. Balasubramanian, M. \& Johnson, C. S. Enabling sodium batteries using lithiumsubstituted sodium layered transition metal oxide cathodes. Adv. Energy Mater. 1 333-336 (2011)

20 Lee, E., Lu, J., Ren, Y., Luo, X., Zhang, X., Wen, J., Miller, D., DeWahl, A., Hackney, S. \& Key, B. Layered P2/O3 intergrowth cathode: toward high power Na-ion batteries. Adv. Energy Mater. 4, 1400458 (2014).
21 Yabuuchi, N., Hara, R., Kajiyama, M., Kubota, K., Ishigaki, T., Hoshikawa, A. \& Komaba, S. New 02/P2-type Li-excess layered manganese oxides as promising multifunctional electrode materials for rechargeable Li/Na batteries. Adv. Energy Mater. 4 1301453 (2014).

22 Xu, J., Lee, D. H., Clément, R. I. J., Yu, X., Leskes, M., Pell, A. J., Pintacuda, G., Yang X.-Q., Grey, C. P. \& Meng, Y. S. Identifying the critical role of Li substitution in P2-Na X [Li y Ni z Mn1-y-z] $02(0<x, y, z<1)$ intercalation cathode materials for high-energy Na-ion batteries. Chem. Mater. 26, 1260-1269 (2014).

23 Lee, D. H., Xu, J. \& Meng, Y. S. An advanced cathode for Na-ion batteries with high rate and excellent structural stability. Phys. Chem. Chem. Phys. 15, 3304-3312 (2013).

24 Jung, Y. H., Christiansen, A. S., Johnsen, R. E., Norby, P. \& Kim, D. K. In situ X-ray diffraction studies on structural changes of a P2 layered material during electrochemical desodiation/sodiation. Adv. Funct. Mater. 25, 3227-3237 (2015).

25 Ong, S. P., Chevrier, V. L., Hautier, G., Jain, A., Moore, C., Kim, S., Ma, X. \& Ceder, G. Voltage, stability and diffusion barrier differences between sodium-ion and lithium-ion intercalation materials. Energy Environ. Sci. 4, 3680-3688 (2011).

26 Yabuuchi, N., Kubota, K., Dahbi, M. \& Komaba, S. Research development on sodium-ion batteries. Chem. Rev. 114, 11636-11682 (2014).

27 Komaba, S., Yabuuchi, N., Nakayama, T., Ogata, A., Ishikawa, T. \& Nakai, I. Study on the reversible electrode reaction of $\mathrm{Na} 1-\mathrm{xNiO} .5 \mathrm{MnO} 0.502$ for a rechargeable sodium-ion battery. Inorg. Chem. 51, 6211-6220 (2012).

28 Guo, S., Yu, H., Liu, P., Ren, Y., Zhang, T., Chen, M., Ishida, M. \& Zhou, H. Highperformance symmetric sodium-ion batteries using a new, bipolar 03-type material, $\mathrm{Na}$ $0.8 \mathrm{Ni} 0.4 \mathrm{Ti} 0.60$ 2. Energy Environ. Sci. 8, 1237-1244 (2015)

29 Berthelot, R., Carlier, D. \& Delmas, C. Electrochemical investigation of the P2-NaxCoO2 phase diagram. Nat. Mater. 10, 74-80 (2011).

30 Guignard, M., Didier, C., Darriet, J., Bordet, P., Elkaïm, E. \& Delmas, C. P2-NaxVO2 system as electrodes for batteries and electron-correlated materials. Nat. Mater. 12, 74-80 (2013).

31 Wang, Y. S., Yu, X. Q., Xu, S. Y., Bai, J. M., Xiao, R. J., Hu, Y. S., Li, H., Yang, X. Q. Chen, L. \& Huang, X. A zero-strain layered metal oxide as the negative electrode for long-life sodium-ion batteries. Nat. Commun. 4, 2365 (2013).

32 Rudola, A., Saravanan, K., Mason, C. W. \& Balaya, P. Na2Ti307: an intercalation based anode for sodium-ion battery applications. J. Mater. Chem. A 1 , 2653-2662 (2013).

33 Shirpour, M., Cabana, J. \& Doeff, M. New materials based on a layered sodium titanate for dual electrochemical $\mathrm{Na}$ and $\mathrm{Li}$ intercalation systems. Energy Environ. Sci. 6 , 2538-2547 (2013).

34 Sun, Y., Zhao, L., Pan, H. L., Lu, X., Gu, L., Hu, Y. S., Li, H., Armand, M., Ikuhara, Y., Chen, L. \& Huang, $X$. Direct atomic-scale confirmation of three-phase storage mechanism in Li4Ti5012 anodes for room-temperature sodium-ion batteries. Nat. Commun. 4, 1870 (2013).

35 Momma, K. \& Izumi, F. VESTA: a three-dimensional visualization system for electronic and structural analysis. J. Appl. Crystallogr. 41, 653-658 (2008).

36 Kresse, G. \& Furthmüller, J. Efficient iterative schemes for ab initio total-energy calculations using a plane-wave basis set. Phys. Rev. B 54, 11169 (1996).

37 Blöchl, P. E. Projector augmented-wave method. Phys. Rev. B 50, 17953 (1994).

38 Perdew, J. P., Burke, K. \& Ernzerhof, M. Generalized gradient approximation made simple. Phys. Rev. Lett. 77, 3865 (1996).

39 Mills, G., Jónsson, H. \& Schenter, G. K. Reversible work transition state theory: application to dissociative adsorption of hydrogen. Surf. Sci. 324, 305-337 (1995).

40 Weppner, W. \& Huggins, R. A. Determination of the kinetic parameters of mixed-conducting electrodes and application to the system Li3Sb. J. Electrochem. Soc. 124, 1569-1578 (1977).

41 Guo, S., Yu, H., Jian, Z., Liu, P., Zhu, Y., Guo, X., Chen, M., Ishida, M. \& Zhou, H. A high-capacity, low-cost layered sodium manganese oxide material as cathode for sodium-ion batteries. ChemSusChem 7, 2115-2119 (2014).

42 Larson, A. C. \& Von Dreele, R. B. GSAS: General Structure Analysis System (LANSCE, MS-H805, Los Alamos, NM, 1994).

43 Toby, B. H. EXPGUI, a graphical user interface for GSAS. J Appl. Crystallogr. 34 210-213 (2001).

44 Mo, Y., Ong, S. P. \& Ceder, G. Insights into diffusion mechanisms in P2 layered oxide materials by first-principles calculations. Chem. Mater. 26, 5208-5214 (2014).

This work is licensed under a Creative Commons Attribution 4.0 International License. The images or other third party material in this article are included in the article's Creative Commons license, unless indicated otherwise in the credit line; if the material is not included under the Creative Commons license, users will need to obtain permission from the license holder to reproduce the material. To view a copy of this license, visit http://creativecommons.org/licenses/by/4.0/ 